\title{
Drivers' adoption of electronic payment in the Spanish toll road network
}

\author{
Javier Heras-Molina $^{1} \cdot$ Juan Gomez $^{1} \cdot$ José Manuel Vassallo $^{1}$
}

\begin{abstract}
Electronic Toll Collection (ETC) systems are based on tags, on-board units associated to personal bank accounts, used for paying tolls electronically. Despite the benefits associated to their use, acknowledged by public authorities among other stakeholders, these systems are relentlessly penetrating as a means for paying the use of roads worldwide. However, governments and infrastructure operators still have a great potential to increase the effectiveness and expediency of these mechanisms. Previous literature in this field has focused on analyzing users' perceptions and willingness to pay to use toll roads. However, there is still room for addressing additional aspects such as drivers' adoption of ETC systems in these road networks allowing the payment of tolls electronically. The aim of this paper is to identify the explanatory factors influencing the adoption of ETC technologies by toll road drivers. To that end, we exploit a nationwide survey conducted to road users in interurban toll roads in Spain, and develop a multilevel logit framework to explore users' adoption and position towards the use of electronic tolling. The research concludes that drivers' tag ownership is mainly related to trip-related attributes, while personal socioeconomic characteristics play a minor role. Then, it is not possible to establish specific socioeconomic user market segments to direct policy efforts aimed at increasing the penetration of ETC. Furthermore, according to the results, delivering tag devices for free would be an effective policy measure to encourage individuals adopting electronic tolling and making additional use of toll roads, due to the benefits provided by ETC systems.
\end{abstract}

Javier Heras-Molina

javier.delasheras.molina@upm.es

Juan Gomez

juan.gomez.sanchez@upm.es

José Manuel Vassallo

jvassallo@caminos.upm.es

1 Transport Research Center -TRANSyT- ETSI Caminos, Canales y Puertos, Universidad Politécnica de Madrid, Avda. Profesor Aranguren, 28040 Madrid, Spain 
Keywords Electronic toll collection · Toll roads · On-board unit · Stated preference survey

\section{Introduction}

Over the last few decades, road infrastructure and its associated technologies are becoming more advanced. As a result, new solutions have been adopted by governments, private operators and users in order to improve traffic flow conditions and safety both in urban and interurban roads. Intelligent Transport Systems (ITS) components inside cars, such as onboard units (OBUs), offer automotive services and enable the communication with the vehicle's environment (Hsu and Shih 2015). Among these services, the use of the OBU as a transponder, commonly called tag, has been gaining importance in toll roads as a means to pay tolls electronically without the need to stop in toll plazas.

The use of tags for paying tolls brings several advantages to both users and operators, such as a reduction of travel time in toll plazas, a decrease of air pollutant emissions, a reduction of operating costs (Jou et al. 2013), etc. Due to the general reduction of transport costs-among other benefits-compared to manual toll collection systems, countries are growingly implementing Electronic Toll Collection (ETC) systems in their road networks worldwide. However, different problems-little understanding of ETC services, the cost of acquiring a tag or the lack of transnational interoperability of ETC services-have hindered the potential growth of these technologies.

One of the most important barriers related to the wider implementation of electronic toll payment is the lack of trans-national interoperability observed between ETC systems, as it is the case of e.g. different countries in Central Europe. For this reason, one of the main challenges lies on the adoption of common and interoperable technologies among ETC systems in different nations. Furthermore, road user privacy is a critical factor that may deter drivers from adopting tags, irrespective of their associated advantages. Privacy may also pose extra costs to service providers if common standards are not adopted across different countries.

Nowadays ETC systems are used in most toll road networks around the world. In the United States, many toll road operators have successfully used ITS to administer planning, design, operation, management, and financing of highway facilities (Chang et al. 2016), where ETC systems play a key role. About $70-89 \%$ of the cars in the US have got these devices, and some states plan to make them mandatory (Abari et al. 2015). For example, E-ZPass is a toll collection technology used in 14 states in the Eastern United States, which allows managing traffic congestion through different actions, such as discount plans.

In Europe, ETC systems have been introduced to achieve two broad needs: firstly, improving the efficiency of privately operated toll roads by reducing traditional toll plazas; and secondly, as a means of fulfilling the public policy objective to link road charges to road use according to the mileage driven and vehicle emissions category (Hayward 2015). Furthermore, the European authorities have acknowledged the contribution of ETC in improving road safety, congestion problems and environmental impacts coming from road traffic. In that way, the European Union passed Directive 2004/52/EC with the aim of ensuring interoperability of ETC systems throughout Europe, following the principle "one vehicle, one contract, one on-board unit" (The European Parliament and The Council of the EU 2004), with limited progress up to date. ETC systems are also used in Asian highways, especially in Taiwan and Japan (Mizutani and Uranishi 2008). 
Despite the increasing literature on attitudes towards toll roads (see e.g. Odeck and Kjerkreit 2010), many research gaps remain to be studied, especially those related to the factors influencing the adoption of tags by drivers. Firstly, there are not many previous contributions exploring the use of ETC systems, in contrast with the wide literature on users' perceptions and willingness to pay in toll roads. Secondly, current contributions are focused on specific toll roads (see e.g. Huang and Burris 2015), but there is a need of analyzing the adoption of ETC technologies in wider areas, such as nationwide toll networks, since local/regional differences could be found.

Previous research works on electronic payment systems have been generally focused on measuring the performance of specific technologies on partial aspects, such as electronic toll systems architecture (Caneschi 2007) or safety assessments (Abuzwidah and AbdelAty 2015). There is hence the need for an overall evaluation regarding users' adoption and opinion towards tags for paying tolls. Analyzing users' perceptions to use ETC systems makes sense since, as pointed out by Jou et al. (2011), if promoters can change the impressions about their innovation through the Media or word on mouth, they could directly or indirectly influence potential users' intentions to adopt the innovation. Then, the analysis of the adoption and opinions towards ETC has important policy implications for toll road operators, public administrations and road users.

The aim of this paper is to provide a first insight into the explanatory factors influencing the use of ETC technologies by toll road drivers, a topic insufficiently addressed up to date in the literature, especially for interurban contexts. To that end, we develop two discrete choice models to explore drivers' adoption of ETC and current attitudes towards the use of tags for paying tolls. This analysis is carried out based on a nationwide survey conducted to toll road users in Spain. This country can be considered a representative case of a network comprising both toll and free high capacity roads. Additionally, Spain has a tolled network asymmetrically located throughout the country, since the majority of tolled $\mathrm{km}$ is concentrated in specific regions. This is expected to have caused great differences across regions on users' knowledge and adoption of ETC technologies. These aspects make Spain an interesting case to analyze potential differences in drivers' points of view on ETC systems within a national toll network. The results of this research can contribute to increase the use of electronic toll collection in Spain, thus providing relevant benefits to society in line with the opinion of the EU authorities. Additionally, the results may be considered to make driving by toll roads more appealing, therefore attracting road traffic from low-quality free parallel roads, with potential benefits in terms of road safety and traffic congestion. Consequently, the research has interesting implications for users, public administrations, road operators, and transportation researchers.

The paper is organized as follows. After the introduction, Sect. 2 reviews the state of knowledge on the topic, especially regarding the use of ETC technologies, and briefly introduces the Spanish toll road network. Section 3 outlines the methodology adopted for this research, and describes the survey and the explanatory variables considered for the analysis. Section 4 presents and discusses the results. Finally, Sect. 5 points out the main conclusions and recommendations for further research. 


\section{Literature review}

\section{The use of tags in toll roads}

Different studies have observed that electronic payment remains still low in those toll roads where cash payment is also available (Jou et al. 2013). To overcome this problem, during the last few decades several agreements have been promoted in the international context, such as the promotion of a European Electronic Toll Service (EETS) within the EU (HerasMolina et al. 2016), with limited progress up to date. In the US different interstate agreements have been reached to increase the use of ETC systems, such as the aforementioned EZ-Pass; or agreements between the SunPass, Peach Pass and NC Quick Pass systems, which let drivers move throughout toll roads in Florida, North Carolina and Georgia by using a single electronic transponder.

National agreements in Europe, like Via-T in Spain and Liber- $t$ in France have been promoted by governments and toll operators in order to support economies of scale and a better operation of toll road networks. The Via- $T$ system can be used to pay tolls electronically in Spain and its neighboring regions: Portugal and the south of France. Further details about the Spanish system Via-T are detailed below (see Sect. 2.2). Likewise, Liber$t$ is the French national ETC system for light vehicles operated by the members of the Association of French Motorway Operators (ASFA) on behalf of the French government.

In addition, some toll infrastructure facilities worldwide have implemented fully automated technologies and do not accept cash payments, as it is the case of e.g. the Golden Gate Bridge (2016), Ex-SCUP roads in Portugal (Infraestruturas de Portugal 2016), or the urban toll highways in Santiago de Chile (de Grange et al. 2015).

Under current freeway ETC systems, the widespread use of tags may get more quality information regarding customer trip characteristics, travel behavior and customers' attitude towards services (Memarian et al. 2012). However, the penetration of these technologies has been limited by different issues, such as privacy concerns from users (Jardí-Cedó et al. 2015) or the fact that the cost of owning a tag is ultimately assumed by drivers (Jou et al. 2013), so the system is only of interest for frequent users.

Research on Electronic Toll Collection systems has barely explored drivers' willingness to use tags for paying tolls (Jou et al. 2013). Some studies focus on technological developments or analysis of specific corridors. Other research pieces have explored different issues such as: users' perceptions and willingness to pay tolls, without making a distinction between conventional versus electronic toll payments (Button 1996; Fowler et al. 2006); users' acceptability as a barrier against the introduction of pricing schemes (Schade and Baum 2007; Odeck and Kjerkreit 2010); or users' perceptions towards the implementation of congestion charging schemes (Kottenhoff and Brundell Freij 2009).

Yim (1991) addressed five aspects in order to determine the level of interest in subscribing to an electronic toll collection service for toll bridges in the Bay Area (US). These five aspects were: (1) interest in the ETC service, (2) preferred types of tags, (3) preferred location of the tag within the vehicle, (4) desired method of payment for the ETC service, and (5) perceived benefits of ETC use. Privacy concerns from users is also a factor frequently pointed out in the literature when analyzing the use of ETC. Charged roads usually require toll systems to be equipped with electronic devices, such as cameras or GPS transponders, that track users' position at any time or control all vehicles passing through the control points. This aspect may represent a serious privacy threat influencing drivers' acceptability (Jardí-Cedó et al. 2015). In addition, current laws barely address electronic 
privacy, and given the rapidly changing nature of technology, interpreting the law with respect to privacy is becoming ever more challenging (Persad et al. 2007). Other research work has conducted surveys to gauge how users' experience of paying tolls has changed over the years (Limelight 2012). In this regard, thirteen questions were analyzed by disaggregating the collected data against one independent variable e.g. region, user group or gender. More recently, Huang and Burris (2015) analyzed traffic evolution in the MiamiDade area (US) and found that cash-paying drivers were more sensitive to a change in the toll rate than those drivers paying electronically.

This paper is aimed at providing a first insight into users' adoption of ETC in interurban roads. To that end, we exploit a survey conducted to road users to identify different explanatory factors determining the use of tags in interurban toll road networks. This represents an interesting contribution given that this problem has been generally studied in urban areas (Jou and Huang 2014), especially where congestion charges are implemented (Eliasson 2008; Kaparias and Bell 2012). Our research aims to contribute to the present literature by analyzing a nationwide toll road network which uses only one ETC system, called Via-T. Secondly, it explores potential differences between users' adoption of ETC given a toll network asymmetrically located across regions.

\section{The Spanish toll road network}

As of 2016, Spain has one of the longest high capacity road networks within Europe, with a total of 16,705 km (Ministerio de Fomento 2016). The introduction of toll highway concessions started in Spain in the latest 1960s in order to develop road projects in a period where public budgetary resources were scarce (Matas et al. 2012). Currently, the high capacity network includes $3020 \mathrm{~km}, 18.1 \%$ of which are tolled. This fact makes Spain one of the longest national tolled networks in Europe. However, the Spanish toll network is not symmetrically distributed across the country, since it concentrates on a limited number of regions.

As can be seen in Table 1, few regions (mainly Catalonia, Valencia and Galicia) comprise most of the total toll roads in the country. While these regions have an extended toll network, other parts of the country such as Extremadura or Cantabria are fully provided with free high quality roads. Moreover, for political reasons every toll road in Spain is expected to have a free parallel road available, which is normally a conventional (twolane) road with poorer characteristics. In that respect, it is worth mentioning that the quality of the free parallel road could greatly vary for the network analyzed, finding important differences among regions. For instance, tolled sections competing with free

Table 1 Interurban high capacity and toll road network in some regions of Spain as of 2016

\begin{tabular}{lrccc}
\hline Country/regions & Surface $\left(10^{3} \mathrm{~km}^{2}\right)$ & High capacity network $(\mathrm{km})$ & $\%$ Tolled & Tolled network $(\mathrm{km})$ \\
\hline Spain & 504.6 & 16,705 & 18.1 & 3020 \\
Basque Country & 7.2 & 643 & 38.6 & 248 \\
Catalonia & 32.1 & 1572 & 40.1 & 631 \\
Galicia & 29.6 & 1120 & 29.2 & 327 \\
Madrid & 8.0 & 991 & 16.2 & 161 \\
Valencia & 23.2 & 1420 & 25.8 & 367 \\
\hline
\end{tabular}


highways are numerous in regions such as Madrid, while in the Basque Country or Catalonia the alternative route is usually a conventional road. A wider description of the Spanish toll network can be found in Gomez et al. (2015).

The current Spanish toll network comprises two different types of roads: Tunnels and Interurban road stretches. The first ones apply a fixed toll for crossing them, such as the Artxanda Tunnels. The second ones, which represent $99.6 \%$ of tolled $\mathrm{km}$, have lower unitary prices. Toll rates are fairly homogeneous throughout the country, although each motorway has its own fee structure-maximum tolls are capped by the Government-and tolls applied are overall more expensive in the summer. In addition, the amount varies across vehicle type: toll rates for light vehicles fall around $0.07-0.12 € / \mathrm{km}$, with rates for heavy vehicles being around 50\% higher. Furthermore, tolls scarcely vary during the day, since higher toll rates at peak hours are only applied for some roads in the Madrid metropolitan area. These particular toll roads have moderate volumes of traffic and compete with free high capacity roads within the same corridors, so this scheme is aimed at increasing the charge when the free alternative gets congested and consequently the toll road becomes a more appealing option.

According to the Spanish legislation, tolls are defined as a payment for passage along a road, a tunnel or over a bridge. This payment can be done by cash, credit card or electronically by using ETC devices (tags). In the last decades, Spain has emerged as one of the most active nations in introducing ETC systems, through the so-called Via- $T$ system, which is based on DSRC (Dedicated Short-Range Communications) technology. Its implementation in 2003 supposed an important milestone since it allowed intra-national interoperability between all existing toll concessionaires, whose previous systems were not compatible with each other. Later on, Spain has also achieved technical interoperability with its two neighboring countries, France and Portugal, also using DSRC technology. The adoption of common standards allows Spanish OBUs to be used on different French toll roads. Reciprocally, French OBUs also work in the Spanish Basque region. Other agreements with Portugal have extended the reach of the Spanish OBUs to the entire Portuguese toll road network.

Within the Spanish Via- $T$ system, the user should acquire a transponder which is linked to a bank account or credit card payment means. The DSRC technology employed presents significant advantages such as data management, since it has the ability of not tracking the users' position at any moment but only recording their cross under the toll gantries. Transponders are commercialized via bank entities, and the user has to pay a yearly fee of $€ 35-50$ for owning the device. Regarding the penetration of ETC technologies in Spain, 7000 of the 17,500 daily users pay electronically, according to Bip\&Drive (2016).

As in other nations, toll road operators in Spain offer discounts for frequent users, only applicable to drivers using the ETC system. The amount of the discount depends on the number of passes made through the barrier in the same month in accordance with ratios adopted by private toll road operators. There are also special discounts for certain groups, such as regular service buses, scholar buses or students up to 25 years old. These discounts are cumulative with toll reductions for frequent use. As seems reasonable, the benefits of toll discounts are more relevant in those regions with a higher density of toll roads. For this reason, it is expected that there the knowledge and use of ETC systems would be wider. 


\section{Data and methodology}

This section presents the nationwide survey conducted in Spain in order to identify the key variables that determine users' adoption of electronic devices for paying tolls. Based on these data, a multilevel choice framework is developed.

\section{The data: a nationwide survey in Spain}

In order to explore users' adoption and opinion towards ETC systems, data from a nationwide survey conducted in different Spanish interurban toll roads has been exploited. This survey comprises a sample of 3043 toll road users (frequent, occasional and potential ones), interviewed between October and November 2012, from Monday to Sunday, in order to get a representative sample. The data was collected from personal interviews at services areas, toll areas and petrol stations (for frequent and occasional users); and phone questionnaires for potential users, that is, individuals not using the toll network despite living close to it. Among other issues, respondents reported whether they used devices allowing for electronic payment in toll roads. Further details on the questions addressed in the survey can be found in Appendix 1.

The survey focuses on those regions with a higher density of toll roads. Particularly, we have selected five Spanish regions previously referred to in Sect. 2.2-Catalonia, Valencia, Galicia, Madrid and Basque Country-for the analysis. As can be seen in Table 1, they comprise around $60 \%$ of the Spanish toll network. The network analyzed includes areas with toll roads in operation for a long time, and other territories with more modern toll sections. Moreover, as previously mentioned every toll road in Spain has a free parallel road available, whose quality can greatly vary depending on the region observed. At this point, it should be noted again that while tolled roads in Madrid usually compete with free highways, in other regions such as the Basque Country or Catalonia the alternative route generally has much poorer characteristics.

As we mentioned above, this paper is aimed at identifying the factors that determine the use of electronic toll collection systems by drivers. The adoption of tag devices by toll road users could be related to a number of factors, broadly classified into three main groups. The first one includes socioeconomic characteristics (i.e. age, gender, income, region of residence, or labor status). The second group covers different trip-related attributes such as type of vehicle, trip purpose, or trip frequency. Finally, the third group comprises attitudinal variables specific to individuals, such as their previous awareness on electronic toll collection systems, their perceptions and beliefs towards toll rates and time savings provided by toll facilities, or their personal benefits from the toll policy (Bueno et al. 2017). The questionnaire collected information from individuals covering this three groups of variable (see Appendix 1).

Table 2 summarizes the main characteristics of the sample. The questionnaire collected drivers' socioeconomic characteristics, such as age, gender, level of income, etc. The region of residence is also considered due to the importance of toll roads density in explaining potential differences in users' adoption of ETC, since toll roads are asymmetrical distributed across regions in Spain (Gomez et al. 2015). This heterogeneity is expected to influence respondents' use of ETC devices given the availability of possible discounts or the existence of congestion problems in free parallel routes. In order to properly analyse potential regional differences in users' adoption of ETC, a multilevel methodology is adopted (see Sect. 3.2). The survey also includes travel-related attributes, 
Table 2 Summary of the sample characteristics

\begin{tabular}{|c|c|c|c|}
\hline Variables & Subgroup & Respondents & \%Sample \\
\hline \multicolumn{4}{|l|}{ Socioeconomics characteristics } \\
\hline \multirow[t]{2}{*}{ Gender } & Male & 1645 & 51.3 \\
\hline & Female & 1559 & 48.7 \\
\hline \multirow[t]{5}{*}{ Age } & Under 24 & 173 & 5.4 \\
\hline & From 24 to 34 & 513 & 16.0 \\
\hline & From 35 to 49 & 1335 & 41.7 \\
\hline & From 50 to 64 & 900 & 28.1 \\
\hline & Above 64 & 283 & 8.8 \\
\hline \multirow[t]{5}{*}{ Region } & Catalonia & 640 & 20.0 \\
\hline & Madrid & 634 & 19.8 \\
\hline & Valencia & 652 & 20.3 \\
\hline & Basque Country & 636 & 19.8 \\
\hline & Galicia & 642 & 20.1 \\
\hline \multirow[t]{5}{*}{ Personal income } & Under $20,000 €$ & 916 & 28.6 \\
\hline & From 20,000 to $30,000 €$ & 1116 & 34.8 \\
\hline & From 30,000 to $50,000 €$ & 462 & 14.4 \\
\hline & Above $50,000 €$ & 108 & 3.4 \\
\hline & Not responding & 602 & 18.8 \\
\hline \multicolumn{4}{|l|}{ Trip-related attributes } \\
\hline \multirow[t]{3}{*}{ Type of vehicle } & Car & 2859 & 89.3 \\
\hline & Light van & 232 & 7.2 \\
\hline & Heavy (truck + bus) & 114 & 3.5 \\
\hline \multirow[t]{3}{*}{ Common trip } & Urban & 1044 & 34.3 \\
\hline & Metropolitan & 1482 & 48.7 \\
\hline & Long-distance & 517 & 17.0 \\
\hline \multirow[t]{3}{*}{ Frequency } & Frequent user & 2210 & 69.0 \\
\hline & Occasional user & 705 & 22.0 \\
\hline & Potential user & 288 & 9.0 \\
\hline \multirow[t]{5}{*}{ Trip purpose } & Commuting & 890 & 27.8 \\
\hline & Business & 349 & 10.9 \\
\hline & Weekend leisure & 783 & 24.4 \\
\hline & Holiday leisure & 562 & 17.5 \\
\hline & Other & 332 & 10.4 \\
\hline \multicolumn{4}{|l|}{ Attitudinal variables } \\
\hline \multirow[t]{2}{*}{ Perception on toll rates } & Cheap & 427 & 14.0 \\
\hline & Expensive & 2618 & 86.0 \\
\hline \multirow{3}{*}{$\begin{array}{l}\text { Time savings provided by toll roads } \\
\text { are worthwhile }\end{array}$} & Yes & 2471 & 81.2 \\
\hline & No & 110 & 3.6 \\
\hline & Indifferent & 462 & 15.2 \\
\hline
\end{tabular}


such as type of vehicle, trip frequency or trip purpose, which define the aim and characteristics of the trip. For potential users, trip purpose was not included as they do not use toll roads.

The third group comprises attitudinal variables and drivers' opinions towards toll roads, among others: perceptions towards toll rates (whether they were perceived them as cheap or expensive), personal benefits from the toll policy, or perceptions on travel time savings (whether drivers were satisfied or not with the travel time reduction provided by the toll road in relation with the toll paid). This type of variables have been included in the analysis given their importance in determining individual positions towards tolls and charging issues in many previous research, e.g. Jaensirisak et al. (2005) or Rienstra et al. (1999). As mentioned before, every toll concession in Spain has a free parallel road available, whose quality characteristics can greatly vary in each case. This point enables us to compare users' attitudes depending on the quality of the free alternative since it may constitute a relevant factor to determine drivers' perceptions insofar as it increases the ability to avoid tolls. For this reason, attitudinal factors such as drivers' perceptions of toll rates could play an important role, since a perception of expensive tolls may be related with a lower use of toll roads. Other attitudinal factors frequently mentioned in the literature regarding ETC, such as privacy issues, were not included in the research. The technology adopted in the Spanish ETC system does not have the ability to track the user's position at any moment but only records the toll gantries crossed each month. Additionally, we do not explore a new technology to be implemented but an ETC system in operation for decades. Therefore this ETC system is not expected to generate much privacy concerns on individuals for the case of Spain.

In addition, the survey includes another important variable, which is drivers' previous awareness of the existence of tags as a means to pay tolls. As can be easily assumed, if drivers do not know about the possibility of acquiring a tag, they will hardly ever be able to answer about their view about these devices. In the same way, if drivers do not know the basic characteristics and operation of tag devices, they will not be able to give their opinion about their hypothetical use of a tag. The survey shows that both issues, previous awareness of tag existence and basic knowledge about tag operation and potential benefits for users, are intimately linked to the density of toll roads within the region of residence (see Sect. 4).

Finally, the survey collected further variables regarding users' willingness to pay in interurban toll roads (Gomez et al. 2015) and users' acceptability towards different road pricing schemes (Bueno et al. 2017). The research also considers further aspects which may influence users' attitudes such as unitary toll rates applied and the type of tolled infrastructure (tunnel/interurban section).

The information collected from the survey is exploited to determine the explanatory factors influencing: (1) users' adoption of ETC; and (2) users' willingness to use toll roads more frequently if tags were provided for free. The latter is aimed at exploring the effectiveness of a policy option aimed at encouraging the use of toll roads and promote the adoption of ETC, in line with the EU objectives in the transport field. These two variables collected in the survey constitute the dependent parameters to be analyzed through the choice models developed below (see details in Sect. 3.2).

A first analysis of the sample shows a higher amount of respondents aged between 35 and 49, with an income below 30,000 €, despite the fact that around $20 \%$ of the people surveyed did not report their income level. Concerning the type of vehicle used, the survey has a vast majority of car users $(89.0 \%)$. Moreover, commuting $(27.8 \%)$ and weekend 
leisure $(24.4 \%)$ are the most common trip purposes in the sample, with a high proportion of respondents $(69.0 \%)$ making more than 8 trips per month (frequents users).

Regarding the questions motivating the survey-drivers' tag ownership and drivers' willingness to use toll roads more frequently if tags were provided for free-the sample shows the following findings. Only $21.2 \%$ of the people surveyed owned a tag, and around $50 \%$ of them would use toll roads more frequently if tags were provided for free. Further details at this point are included in Sect. 4.

\section{Methodology: the binary choice model}

As mentioned above, this study estimates two binary choice models to identify the explanatory factors determining drivers' adoption of electronic payment in toll roads. Particularly, the research focuses on analyzing: (1) users' adoption of ETC; and (2) users' willingness to use toll roads more frequently if tags were provided for free. To that end, we adopt a discrete choice framework based on logit specifications. Choice models are frequently used to analyze travelers' perceptions, forecast travelers' behavior under hypothetical scenarios or to understand travelers' reaction and adaptation to different sources of information (Train 2003).

Choice models incorporate the micro-economic theory of consumer behavior and psychological choice behavior, frequently used in transportation research. They are utility maximization models assuming that individuals choose the alternative with the highest utility for them among the options available, (Ben-Akiva and Bierlaire 2003). The utility of each choice can be determined by a number of explanatory variables, and considered as the addition of two different components: observed variables $\left(V_{i k}\right)$, which are the systematic or representative component of the utility; and random components $\left(\varepsilon_{i k}\right)$, comprising the idiosyncratic term:

$$
U_{i k}=V_{i k}+\varepsilon_{i k}=\beta_{k} X_{i k}+\varepsilon_{i k}
$$

where $X_{i k}$ is a vector of explanatory variables influencing individual choices, and $\beta_{k}$ represents a vector of parameters to be estimated fitting the model (Louviere et al. 2008). Given the binary nature (Yes/No) of the choices to be modelled, a binary logit approach has been adopted. Mathematically, according to Gujarati (2003), the probability function that rules the logit model is the logistic distribution:

$$
P_{i}=\frac{1}{1+e^{-V_{i k}}}
$$

Due to the aforementioned heterogeneity we could expect in the adoption of ETC systems across regions for Spain, as in other tolling issues identified for this nation by Gomez et al. (2016), the model framework also incorporates a multilevel approach in addition to the logit specification (multilevel logit model). It represents an extension of classical models to overcome the potential correlation between data observations, caused by hierarchical or nested structures in the data that could happen when e.g. observing different behavior of individuals across groups (regions). This fact could mean that the assumption of independent observations is violated (Koppelman and Bhat 2006), leading to the so-called "atomistic fallacy", with important negative consequences in the results, such as misinterpretation and spurious statistical significances of parameter estimates (Hox 2002).

Based on a more complex structure, multilevel specifications consider a different model for each level of data. This allows exploring inter-group variability, in this case potential 
behavioral differences across users from different regions that may be caused by the different abundance of toll roads throughout Spain. For this research, we apply the standard multilevel approach, based on random coefficients, that has been widely described in the literature (de Leeuw and Meijer 2007).

The modeling framework was assigned a two-level structure ( $\mathrm{i}-\mathrm{j})$, where subscript $\mathrm{i}$ is related to individuals, while $\mathrm{j}$ refers to the regional level. Additionally, the equation comprises random effects at both intercepts and slope parameters, allowing random variations among regions $(\mathrm{j})$, as shown below in a general form:

$$
\begin{gathered}
Y_{i j}^{*}=\beta_{0(n) j}+\beta_{1(n) j} X_{1 i j}+\cdots+\beta_{p(n) j} X_{p i j}+\varepsilon_{i j} ; \\
\beta_{0(n) j}=\beta_{0(n)}+u_{j} ; \beta_{p(n) j}=\beta_{p(n)}+u_{j}
\end{gathered}
$$

where $\beta_{0(n) j}$ is the model intercept, consisting on a fixed intercept $\beta_{0(n)}$ and a random variation $u_{j}$ of this intercept across regions, in a similar way as in Papadimitriou (2014). Then, it allows intercepts to vary randomly at the regional level. In a similar way, $\beta_{1(\mathrm{n}) \mathrm{j}}$ is the coefficient for explanatory variable $X_{1}$, also allowing variability across regions $(j)$. In this respect, a significant random intercept with regard to regions indicates that divergences between responses are due to unobserved regional differences, and not only to differences across respondents. Additionally, a significant random slope with regard to regions means that the influence of a certain explanatory variable $X_{p}$ does significantly vary across regions.

As commonly done in multilevel specifications, the model incorporates explanatory variables influencing utility at two different levels (see Eq. 4). At the individual level, we consider three types of parameters within our modeling approach (see Table 2 above): personal socio-economic characteristics (S); trip-related attributes $(\mathrm{T})$, and general attitudes on toll roads and their characteristics (A). The only explanatory variable included at the regional level $(\mathrm{R})$, regards the abundance of toll roads within each region as it could significantly influence the adoption of ETC systems by users. The, the utility $\left(U_{i k}\right)$ achieved by a certain individual $k$ in region $\mathrm{j}$ for choosing the alternative $i$ can be expressed as follows:

$$
U_{i j k}=f\left(S_{i k}, T_{i k}, A_{i k}, R_{j}\right)
$$

In order to properly analyse regional differences in users' tag ownership, a first model (called "Model 0" or empty model) is initially estimated in order to check the statistical significance of the random effects included, that is, the presence of statistical differences across regions. The results of Model 0 are subsequently compared with the full model including all explanatory variables.

\section{Results and discussion}

This section summarizes the main results from the analyses conducted in this research. The data collected from the survey have been exploited to estimate two binary logit models. First we report some preliminary findings on users' previous awareness of ETC systems. Then we show the modeling results regarding users' tag ownership. Finally, we analyze drivers' willingness to use toll roads more frequently if tags were provided for free. 


\section{Preliminary findings: drivers' previous awareness of ETC systems}

Before reporting the results of the different models, preliminary aspects are displayed with regard to drivers' previous awareness of ETC systems (see Table 3). As can be observed, almost three quarters of total respondents $(74.1 \%)$ expressed their awareness of the existence of ETC systems in Spain. Then, we can assume that ETC services are fairly wellknown among drivers.

The highest rate of awareness corresponds to those respondents aged between 35 and 49 $(80.3 \%)$. By contrast, lower awareness rates are found among elderly people, particularly above 64 years old (58.4\%); and the youngest drivers, from 18 to 24 years old $(66.5 \%)$. This may reflect the low use of ITS by elderly, and the preference for using free parallel roads by young people.

Furthermore, there is a great awareness of ETC systems among users who drive heavy vehicles, both trucks and buses (91.7\%), thus corresponding to staff from transport companies. It seems to be due to the discounts policy of the Via- $T$ system and the different advantages for transport companies, such as centralized payment of tolls. For cars and light vans the awareness is significantly lower, likely because of their lower use of roads when compared to transport companies. Regarding the trip purpose variable, ETC systems are notably known by commuters, that is, people who use toll roads frequently. On the other hand, occasional usage of toll roads (e.g. holiday leisure) is related to lower awareness rates.

Table 3 Drivers' previous awareness of electronic toll collection systems

\begin{tabular}{lll}
\hline & Yes $(\%)$ & No $(\%)$ \\
\hline Total sample & 74.1 & 25.9 \\
Age & & \\
Under 24 & 66.5 & 33.5 \\
From 24 to 34 & 77.6 & 22.4 \\
From 35 to 49 & 80.3 & 19.7 \\
From 50 to 64 & 69.5 & 30.5 \\
Above 64 & 58.4 & 41.6 \\
Region & & \\
Catalonia & 82.7 & 17.3 \\
Madrid & 71.1 & 28.9 \\
Valencia & 65.4 & 34.6 \\
Basque Country & 79.0 & 21.0 \\
Galicia & 72.5 & 27.5 \\
Type of vehicle & & \\
Car & 73.6 & 26.4 \\
Light Van & 71.4 & 28.6 \\
Heavy (truck + bus) & 91.7 & 8.3 \\
Trip purpose & & \\
Commuting & 76.9 & 23.1 \\
Business & 84.8 & 15.2 \\
Weekend leisure & 68.1 & 31.9 \\
Holiday leisure & 56.8 & 43.2 \\
Other & 69.1 & 30.9 \\
\hline
\end{tabular}


In addition, results show that, as could be initially expected, the awareness of ETC systems is not homogenous throughout the country since it varies in line with the density of toll roads in each region. In Catalonia, a region with an extensive toll road network, users' awareness of ETC systems goes up to $82.7 \%$. By contrast, this percentage is only $65.4 \%$ in Valencia. As we mentioned before, the policy of discounts offered to drivers seems to have an important influence in this aspect. This regional heterogeneity observed in the sample seems to support the adoption of a multilevel specification for the modelling approach.

Table 4 Tendency of variables for drivers' tag ownership

\begin{tabular}{|c|c|c|c|}
\hline & & Yes $(\%)$ & No $(\%)$ \\
\hline Total sample & & 21.2 & 78.8 \\
\hline \multicolumn{4}{|l|}{ Socioeconomics characteristics } \\
\hline \multirow[t]{4}{*}{ Age } & Under 24 & 14.9 & 85.1 \\
\hline & From 24 to 34 & 19.9 & 80.1 \\
\hline & From 35 to 49 & 24.3 & 75.7 \\
\hline & Above 50 & 19.1 & 80.9 \\
\hline \multirow[t]{5}{*}{ Region } & Catalonia & 29.1 & 70.9 \\
\hline & Madrid & 15.3 & 84.7 \\
\hline & Valencia & 16.2 & 83.8 \\
\hline & Basque Country & 27.6 & 72.4 \\
\hline & Galicia & 17.5 & 82.5 \\
\hline \multirow[t]{3}{*}{ Personal income } & Under $20,000 €$ & 20.9 & 79.1 \\
\hline & From 20,000 to $30,000 €$ & 22.9 & 77.1 \\
\hline & Above $30,000 €$ & 31.2 & 68.8 \\
\hline \multicolumn{4}{|l|}{ Trip-related attributes } \\
\hline \multirow[t]{3}{*}{ Type of vehicle } & Car & 19.0 & 81.0 \\
\hline & Light van & 24.9 & 75.1 \\
\hline & Heavy (truck + bus) & 63.6 & 36.4 \\
\hline \multirow[t]{3}{*}{ Common trip } & Urban & 14.1 & 85.9 \\
\hline & Metropolitan & 19.5 & 80.5 \\
\hline & Long-distance & 38.1 & 61.9 \\
\hline \multirow[t]{5}{*}{ Trip purpose } & Commuting & 21.4 & 78.6 \\
\hline & Business & 36.6 & 63.4 \\
\hline & Weekend leisure & 15.3 & 84.7 \\
\hline & Holiday leisure & 12.9 & 87.1 \\
\hline & Other & 15.0 & 85.0 \\
\hline \multicolumn{4}{|l|}{ Attitudinal variables } \\
\hline \multirow[t]{2}{*}{ Perception on toll rates } & Expensive & 24.8 & 75.2 \\
\hline & Cheap & 20.6 & 79.4 \\
\hline \multirow[t]{2}{*}{ Time savings provided by toll roads are worthwhile } & No & 12.2 & 87.8 \\
\hline & Yes & 21.6 & 78.4 \\
\hline Previous awareness about ETC systems & & 27.5 & 72.5 \\
\hline
\end{tabular}




\section{Drivers' tag ownership}

Results for the analysis exploring drivers' tag ownership are commented below. Before showing the results for the modelling approach, in Table 4 we include some trends on survey responses with respect to some explanatory variables. As can be seen, only around $20 \%$ of respondents reported to have a tag, which can be considered rather low. Among other results, we found that tag ownership seems to increase in parallel to the level of income and seems to be strongly related to the type of vehicle-higher use of ETC systems among drivers of heavy vehicles_and the common trip made-higher tag ownership rates among those individuals making long-distance trips-. We can also observe that the region of residence seems to greatly influence ETC adoption, since tag ownership is higher in those regions with a denser toll network, such as Catalonia (29.1\%) or the Basque Country (27.6\%). By contrast, the use of electronic payment is noticeably lower in regions with a lower presence of toll roads, such as Madrid (15.3\%). These issues need to be more properly addressed through the modelling approach detailed below.

After this preliminary overview, a multilevel logit specification has been developed to explore drivers' tag ownership. Particularly, this model (Model 1) estimates the probability of owning a tag depending on a set of explanatory variables. This analysis may be useful to determine those factors that may contribute to a greater adoption of ETC systems among drivers. Prior to running the binomial logit, different tests for checking multicollinearity among the explanatory variables were conducted according to Gujarati (2003), showing no significant interactions.

All explanatory variables used in the model are categorical, so choosing a base case as a reference is needed to properly interpret modeling results (see Table 5). This enables us to determine whether users' answers, either positive or negative, are statistically significant when compared with the base case. Regarding the region parameter, Galicia is selected as the base case because it seems to represent an intermediate position in terms of users' awareness towards electronic payment and the density of the tolled network. With regard to frequency and trip purpose variables, frequent usage and commuting have been selected as the base case in order to check potential differences with other situations.

Before running the full model, within a multilevel approach it is necessary to previously run a so-called Model 0 or "empty model" to test whether random variations across regions are a significant part of the total variation between responses. As can be seen in Table 5 (left-hand side), unobserved effects across regions are highly significant ( $p$ value $=0.000$ ), therefore there is evidence of statistically significant disparities between regions regarding tag ownership. In line with the findings commented above, those regions with a more dense toll network show higher rates of ETC adoption. For instance, random intercepts for Catalonia (0.42) or the Basque Country (0.35) are noticeably higher when compared to result for other regions with a less dense toll road network, such as Madrid $(-0.32)$.

Subsequently, the full model containing all explanatory variables is estimated. Table 5 includes (right-hand side) the final modelling results once removing those explanatory variables not being statistically significant. To that end, different Likelihood-ratio (LR) tests have been used to check that no change in the overall fitting of the model is produced when removing these parameters. Regarding the final model, the signs of the regression coefficients and their statistical and practical significance are in line with the expected results. As can be seen, the results confirm that, from a statistical point of view ( $p$ value $<0.05$ ), drivers' tag ownership is influenced by trip-related attitudes and, to a 


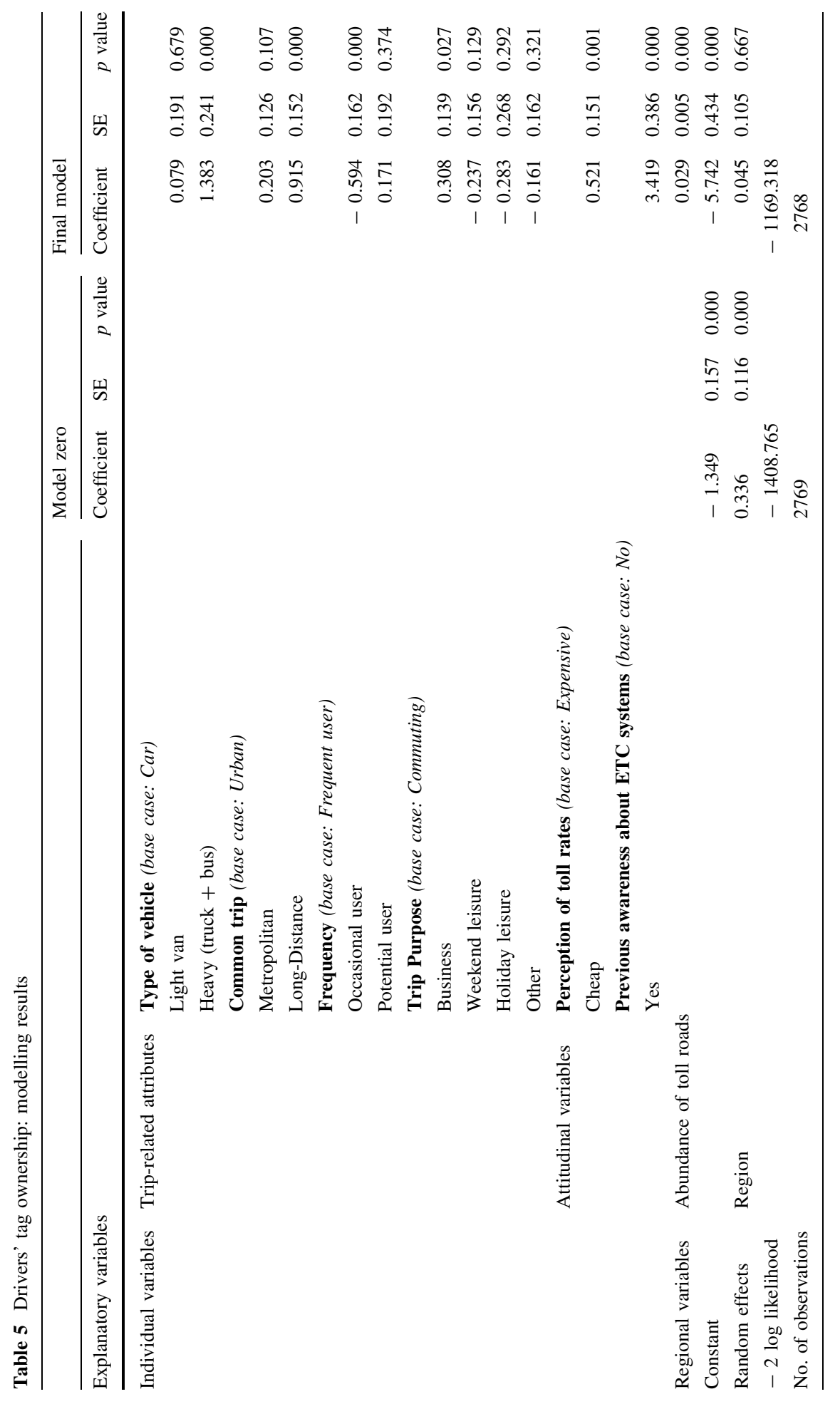


lesser extent, by attitudinal variables. This greatly contrasts with the results found for individual socioeconomic characteristics.

According to the modeling results, socioeconomic characteristics did not evidence to play a role when determining users' ownership of ETC devices, since they are not statistically significant at $95 \%$ ( $p$ value $>0.05$ ). Notable among these variables are age, gender and income level, for which a statistical relationship with ETC adoption cannot be concluded from this analysis. From a policy perspective, this result point out that it is not possible to establish specific socioeconomic user market segments to direct policy efforts aimed at increasing the penetration of ETC, given that all variables of this type are non-significant.

Regarding trip-related attributes, they seem to strongly influence the adoption of electronic toll payment by users, with the type of vehicle-greater adoption for heavy vehicles-, the frequency of trips-greater adoption for frequent users-and the trip purpose-greater adoption for business trips-among the more relevant explanatory variables. Firstly, the research shows an important difference between cars and heavy vehicles, probably because the latter make a more intense use of roads and therefore can greatly benefit from travel time reductions in toll plazas and toll discounts offered when adopting ETC devices. The trip purpose "business" is also important to decide whether acquiring a tag or not, while other trip purposes-like weekend leisure or holiday leisurerelated to a lower use of toll roads, are not significant. Statistically significant relationships can also be noticed for the common trip made by the user. At this point, we found that drivers usually making interurban trips show a greater use of electronic payment. This seems reasonable given that the Spanish toll road network is almost purely interurban, with very few sections in metropolitan contexts.

As for attitudinal variables, people perceiving that tolls are cheap show a higher probability of owning a tag. This may be due the fact those individuals may travel by toll roads more frequently and, therefore, be more familiar with the benefits offered by electronic toll payment. We also included a variable to control for the previous awareness of ETC systems, since as stated above, drivers will not be able to properly decide owning a tag if they are not previously aware of electronic payment devices.

Regarding regional variables, we found that tag ownership is higher in those regions with a higher density of toll roads. It is also worth noting that unobserved effects across regions almost disappear in the full model. As can be seen in Table 5, random coefficients become very close to zero $(0.045)$ and non-statistically significant ( $p$ value $=0.66$ ) after including explanatory parameters in the model. Then, it may be concluded that regional differences initially identified on users' adoption of ETC are appropriately explained with the full model.

To sum up, modelling results indicate that ETC ownership is strongly associated to the use of the toll facilities, but not to a particular socioeconomic user profile. Furthermore, the fact that attitudinal variables explain better tag ownership than socioeconomic characteristics has important policy implications to encourage the adoption of ETC. Regarding the goodness of fit, the model showed a log-likelihood of - 1169. A Likelihood-ratio (LR) test was conducted to check that the final model is overall significant when compared to Model $0(p$ value $=0.000)$.

\section{Drivers' willingness to use toll roads more frequently if tags were provided for free}

Model 2 explores drivers' positions towards policy options on ETC. Particularly, we focus on the hypothetical provision of free tags to users with the objective of encouraging the 
adoption of ETC and promoting the use of toll roads. As pointed out above, the aim of increasing the use of toll roads is mainly related with attracting road demand from free parallel roads, generally of low quality in Spain, thus improving road safety and traffic congestion in the road network. Then, Model 2 analyses whether users would use toll roads more frequently if tags were provided for free. However, due to the overall scope of the survey, respondents were not specifically asked how much they would increase or reduce their use of toll roads or whether the measure is acceptable or not. This question in the survey is motivated by the fact that the cost of owning a tag seems to be a factor especially limiting the penetration rate of electronic tolling among users. As it was already mentioned, in Spain drivers have to pay a yearly fee of around $35-50 €$ for owning a tag, so adopting electronic tolling could not be interesting for non-frequent users due to their scarce use of toll discounts. Other interesting policy options to be potentially considered for promoting the adoption of ETC, such as adding an extra fee for manual payment, were not included since the focus was on the main barrier identified for the case of Spain, that is, the cost of owning a tag. Privacy issues may also play a role in certain cases, but we can expect a very limited effect for Spain given that the type of ETC technology adopted in this nation does not track the users' position.

Preliminary findings on users' willingness to use toll roads more frequently if tags were free are displayed in Table 6 for different groups of respondents. It is important to notice that the number of observations is significantly reduced (394 observations), since this question was only formulated to respondents who were familiar with ETC devices, but did not have a tag. At first glance, we can see that delivering free tags would be an effective policy measure to increase toll road use, given that around $50 \%$ of respondents show a positive response. With few exceptions, this percentage is fairly stable throughout the sample and across groups of explanatory variables, as can be seen in Table 6. Nevertheless, some specific groups of users, such as drivers under 24, heavy vehicles drivers or residents in Madrid, seem that would specially increase their use of toll roads according to the preliminary trends.

Particularly, when compared to other categories, the rate of positive responses is noticeably higher for young people (aged under 24), higher levels of income (above $30,000 €$ ), heavy vehicle drivers or individuals making long-distance trips. It is also worth noticing the higher share of positive responses observed in Madrid, probably indicating that the current cost associated to ETC devices is a barrier to increase toll roads use in this region. At this point, answering "No" to this question means that individuals would not use more the toll road despite the gratuity of the tag. That would mean that the demand of electronic payment is mainly inelastic, as it seems to mainly happen in e.g. the region of Galicia.

In order to analyse the potential implementation of this policy measure more rigorously, a binary multilevel model has been estimated (Model 2). Again, the results for the empty model (left-hand side in Table 7) evidenced that unobserved effects across regions are highly significant ( $p$ value $=0.023$ ) regarding the willingness to use toll roads more frequently if tags were free. In line with the preliminary findings, random intercepts are particularly relevant for Madrid (0.37), then drivers in this region show a higher likelihood of using toll roads more frequently if they would not assume the cost of owning a tag. This may be related to the possibility of using metropolitan toll roads in Madrid to avoid the congestion that commonly happens at the peak hour in the free high capacity roads competing with them. By contrast, random intercepts are almost zero or negative for other regions with a higher presence of toll roads, such as Catalonia $(-0.11)$ or Galicia 
Table 6 Drivers' willingness to use toll roads more frequently if tags were provided for free

\begin{tabular}{|c|c|c|c|}
\hline & & Yes $(\%)$ & No $(\%)$ \\
\hline Total sample & & 50.2 & 49.8 \\
\hline \multicolumn{4}{|l|}{ Socioeconomics characteristics } \\
\hline \multirow[t]{2}{*}{ Gender } & Male & 48.9 & 51.1 \\
\hline & Female & 50.6 & 49.4 \\
\hline \multirow[t]{4}{*}{ Age } & Under 24 & 61.4 & 38.6 \\
\hline & From 24 to 34 & 55.9 & 44.1 \\
\hline & From 35 to 49 & 49.4 & 50.6 \\
\hline & Above 50 & 45.6 & 54.4 \\
\hline \multirow[t]{5}{*}{ Region } & Catalonia & 45.5 & 54.5 \\
\hline & Madrid & 61.9 & 38.1 \\
\hline & Valencia & 49.5 & 50.5 \\
\hline & Basque Country & 47.3 & 52.7 \\
\hline & Galicia & 41.6 & 58.4 \\
\hline \multirow[t]{3}{*}{ Personal income } & Under $20,000 €$ & 46.3 & 53.7 \\
\hline & From 20,000 to $30,000 €$ & 40.9 & 59.1 \\
\hline & Above $30,000 €$ & 63.5 & 36.5 \\
\hline \multicolumn{4}{|l|}{ Trip-related attributes } \\
\hline \multirow[t]{3}{*}{ Type of vehicle } & Car & 49.9 & 50.1 \\
\hline & Light van & 42.8 & 57.2 \\
\hline & Heavy (truck + bus) & 68.8 & 31.2 \\
\hline \multirow[t]{3}{*}{ Common trip } & Urban & 49.4 & 50.6 \\
\hline & Metropolitan & 46.8 & 53.2 \\
\hline & Long-distance & 63.5 & 36.5 \\
\hline \multirow[t]{5}{*}{ Trip purpose } & Commuting & 48.3 & 51.7 \\
\hline & Business & 59.9 & 40.1 \\
\hline & Weekend leisure & 52.2 & 47.8 \\
\hline & Holiday leisure & 54.4 & 45.6 \\
\hline & Other & 42.5 & 57.5 \\
\hline \multicolumn{4}{|l|}{ Attitudinal variables } \\
\hline \multirow[t]{2}{*}{ Perception on toll rates } & Expensive & 47.8 & 52.2 \\
\hline & Cheap & 50.0 & 50.0 \\
\hline \multirow[t]{2}{*}{ Time savings provided by toll roads are worthwhile } & No & 51.5 & 48.5 \\
\hline & Yes & 39.4 & 60.6 \\
\hline \multirow[t]{2}{*}{ Previous awareness about ETC systems } & No & 52.7 & 47.3 \\
\hline & Yes & 44.2 & 55.8 \\
\hline
\end{tabular}

$(-0.22)$. This result evidences that users in these regions are less prone to increase their use of toll roads because of the burden of tolls they currently suffer.

Regarding the results of the full model (right-hand side in Table 7), no clear trends can be identified regarding the importance of socioeconomic characteristics, trip-related attributes or attitudinal variables when explaining drivers' willingness to use toll roads more frequently if tags were provided for free. This result is in line with the preliminary 


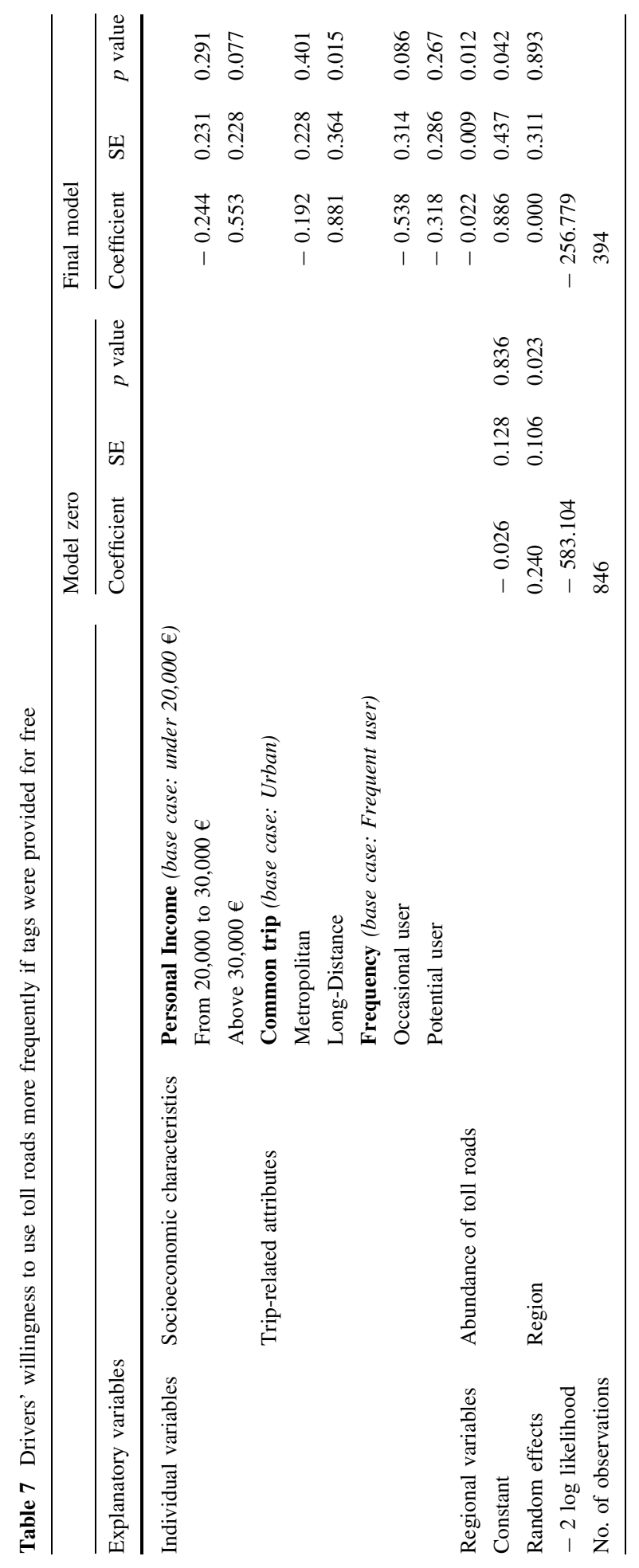


findings above, which showed a quite homogeneous likelihood throughout the sample to increase the use of toll roads. Then, only a handful of variables resulted statistically significant at the $95 \%$ confidence level, not belonging to a particular group of parameters. Given this fact and the reduced number of observations, we kept those explanatory variables with at least one significant category at the $90 \%$ level. This criterion was confirmed by a Likelihood-ratio test, suggesting to keep these parameters in the full model.

According to the modelling results, only three explanatory variables (apart from regional issues) resulted to significantly influence drivers' willingness to use toll roads more frequently if tags were provided for free. These parameters are level of income, trip frequency and the common trip frequently made. Regarding the level of income, drivers' willingness to use toll roads more frequently if tags were provided for free is close to be significant for income levels above $€ 30,000$. We may assume that this segment of the demand is more elastic to adopt a diversion to charged roads. Nevertheless, other socioeconomic characteristics, such as age or gender, did not evidence to play a role.

We can also observe in Table 7 that long-distance trips show a positive influence in the probability of using toll roads more frequently if tags were free. Again, this can be explained by the interurban nature of the Spanish toll road network and the higher monetary discounts to be benefited in long trips if drivers use a tag. Regarding trip frequency, occasional drivers seem to show a lower probability to increase their use of toll roads when compared to frequent users, but no statistically significant results are found at the $95 \%$ level. By contrast, it may seem somehow surprising - in the light of some preliminary findings above - that the model does not provide statistically significant results for certain variables, such as type of vehicle. At this point, we may expect a more positive position of truck and bus drivers towards increasing their use of toll roads in case tags were free, given that they make a very intense use of the road network. Nevertheless, this effect may be partially captured by other variables such as Frequency of trips, close to be significant in the model.

As for attitudinal variables, none of them showed statistically significant results in the model. For instance, perceiving the toll price to be expensive could be strongly associated with a higher probability of increasing the use of toll roads given the availability of discounts. Although the coefficient has the expected sign, it is not statistically significant. This is also the case of the variable controlling for users' perceptions on time savings provided by the toll facility.

Regarding regional variables, those regions with a higher density of toll roads show lower willingness to make additional use of toll roads in case tags were free. This could be associated to the high burden of tolls currently supported by drivers living in these areas. It is also worth noting that unobserved effects across regions almost disappear in the full model. As can be seen in Table 7, again random coefficients become very close to zero and non-statistically significant ( $p$ value $=0.89$ ) after including explanatory parameters in the model, so regional differences initially identified are appropriately explained with the full model. Regarding the goodness of fit of the model, the model showed a log-likelihood of - 256. A Likelihood-ratio (LR) test was adopted to check that the final model is overall significant when compared to Model 0 ( $p$ value $=0.000)$.

From the results of Model 2, we can conclude that there are no clear trends regarding the type of explanatory variables that would increase the use of toll roads in case the devices were provided for free. For this reason, there is no clear group of users who would increase their use of toll roads in case of any change in the cost of tag devices. By contrast, it seems that the share of positive responses is quite constant throughout the sample, with around $50 \%$ of individuals willing to make additional use of toll roads. In any way, a very 
positive conclusion can be extracted: a wide position towards increasing the use of toll roads is observed among users. Since around $50 \%$ of respondents would be willing to adopt ETC and make additional use of the toll network, this policy clearly makes toll roads more attractive, probably due to the possibility to freely benefit from cashless payments and travel time reductions offered by ETC. Therefore, delivering free tags to users evidenced to be an effective policy measure to be adopted by toll operators and public administrations, given the overall effectiveness observed across all types of users. Nevertheless, this should be taken with caution given the limited sample size who answered this question.

\section{Conclusions and further research}

According to the literature on electronic toll payment (Saber et al. 2013), the increase in the use of OBUs will improve real-time route assignment thereby balancing the load between the different road segments and offering the best quality to the drivers. The results from this research show particular determinants to explain the use of electronic payment mechanisms in toll roads and also leave other aspects to be investigated in more detail.

The first conclusion is that drivers' adoption of tag devices did not evidence to be influenced by individual socioeconomic characteristics, such as income or age. The only variable of this type that resulted to statistically influence the adoption of ETC is the region of residence, in the case of Spain strongly related to the abundance of toll roads given the asymmetry of the toll network and, as a consequence, clearly linked with transport-related conditions. Then, from a policy perspective, it is not possible to determine the socioeconomic profile of road users currently less supportive of paying tolls electronically, to whom direct policy efforts aimed at increasing the penetration of ETC

The second conclusion, connected with the first one, is that owning a tag device is strongly associated to the use of the toll facilities, particularly to trip-related attributes such as trip frequency, trip purpose and the fact of driving for professional reasons (staff of transport companies). This is important in order to identify the possibilities and market segments to increase the use of ETC systems under current conditions.

In third place, according to the results, delivering free tags to users evidenced to be an effective policy measure to encourage the adoption of ETC and promote the use of toll roads among users. At least for the case of Spain, the effectiveness of this measure is fairly constant among respondents, despite some subgroups with a higher likelihood to increase the use of toll roads are identified. Then delivering free tags, or finding mechanisms to reduce tag costs assumed by users, would be an effective policy to be adopted by toll operators and public administration aimed at promoting a wider adoption of ETC in line with the EU objectives.

In addition, it should be noted that the analysis conducted has some limitations. Firstly, the sample size obtained from this survey in Spain can be considered quite limited, especially for the analysis conducted on users' willingness to make additional use of toll roads in case tags were free. Secondly, due to the technical characteristics of the Spanish ETC system-not tracking users' position-, privacy issues were not explicitly addressed in the research. Moreover, it was not possible to explore the influence of interoperability problems on ETC adoption, since in the very particular case of Spain, transnational interoperability has been achieved with its neighboring countries.

The results of the research can be generalized to other markets, especially those where electronic toll collection is not mandatory or still remains far from being the majority 
alternative. This would be the case of e.g. Southern European countries applying concession tolls, such as France, Portugal or Italy; and Latin American countries, like Mexico or Argentina. However, in other markets where most drivers use toll roads, such as United States, most drivers use on-board units. Nevertheless, the research did not explore the effectiveness of potential alternative measures to increase the adoption of ETC, such as adding an extra fee for manual payments.

From the results of this paper, some aspects can be pointed out for further research. Futures studies could attempt to extend this analysis to a greater range of explanatory variables, especially on drivers' awareness to use toll roads more frequently if tags were provided for free. In addition, differences on drivers' adoption of electronic payments should also be analyzed through other perspectives by using e.g. variables related to psychology and sociology. At this point, further efforts are needed to explore the influence that users' privacy concerns can have on the adoption of ETC systems. The importance of technical aspects such as lack of transnational interoperability of ETC services also represent a key aspect to be explored in future research.

Acknowledgements The authors wish to thank the Spanish Ministry of Economy and Competitiveness (MINECO) which has funded the project TRA2015-64723-R.

\section{Appendix}

\section{See Table 8 .}

Table 8 Variables measured and questions addressed in the survey

\begin{tabular}{|c|c|c|c|}
\hline Variable & & Question addressed & Options provided \\
\hline \multirow[t]{4}{*}{$\begin{array}{l}\text { Socioeconomic } \\
\text { characteristics }\end{array}$} & Gender & - & $\begin{array}{l}\text { Male } \\
\text { Female }\end{array}$ \\
\hline & Age & $\begin{array}{l}\text { Where do you place your age in the } \\
\text { following intervals? }\end{array}$ & $\begin{array}{l}\text { Under } 24 \\
\text { From } 24 \text { to } 34 \\
\text { From } 35 \text { to } 49 \\
\text { From } 50 \text { to } 64 \\
\text { Above } 64\end{array}$ \\
\hline & Region & - & $\begin{array}{l}\text { Catalonia } \\
\text { Madrid } \\
\text { Valencia } \\
\text { Basque Country } \\
\text { Galicia }\end{array}$ \\
\hline & Income & $\begin{array}{l}\text { Where do you put your personal income in } \\
\text { the following intervals? }\end{array}$ & $\begin{array}{l}\text { Under } 20,000 € \\
\text { From } 20,000 € \text { to } \\
30,000 € \\
\text { From } 30,000 € \text { to } \\
50,000 € \\
\text { Above } 50,000 € \\
\text { Not responding }\end{array}$ \\
\hline
\end{tabular}


Table 8 continued

\begin{tabular}{|c|c|c|c|}
\hline Variable & & Question addressed & Options provided \\
\hline \multirow[t]{4}{*}{$\begin{array}{l}\text { Trip-related } \\
\text { attributes }\end{array}$} & Type of vehicle & - & $\begin{array}{l}\text { Car } \\
\text { Light van } \\
\text { Heavy (truck }+ \text { bus) }\end{array}$ \\
\hline & Common trip & $\begin{array}{l}\text { What is your most common trip when you } \\
\text { use toll roads? }\end{array}$ & $\begin{array}{l}\text { Urban } \\
\text { Metropolitan } \\
\text { Long-distance }\end{array}$ \\
\hline & Frequency & $\begin{array}{l}\text { How often do you use toll roads, } \\
\text { considering the following intervals? }\end{array}$ & $\begin{array}{l}\text { Frequent user }(>8 \\
\text { trips per mouth) } \\
\text { Occasional user }(<8 \\
\text { trips per mouth) } \\
\text { Potential user (never } \\
\text { used it before) }\end{array}$ \\
\hline & Trip purpose & $\begin{array}{l}\text { What is the most common trip purpose } \\
\text { when you use toll roads? }\end{array}$ & $\begin{array}{l}\text { Commuting } \\
\text { Business } \\
\text { Weekend leisure } \\
\text { Holiday leisure } \\
\text { Other }\end{array}$ \\
\hline \multirow[t]{3}{*}{$\begin{array}{r}\text { Attitudinal } \\
\text { variables }\end{array}$} & $\begin{array}{l}\text { Perception of } \\
\text { toll rates }\end{array}$ & In your opinion, current toll rates are... & $\begin{array}{l}\text { Cheap } \\
\text { Expensive }\end{array}$ \\
\hline & $\begin{array}{l}\text { Perception on } \\
\text { time savings }\end{array}$ & $\begin{array}{l}\text { In your opinion, using toll roads makes } \\
\text { you save time? }\end{array}$ & $\begin{array}{l}\text { Yes } \\
\text { No } \\
\text { Indifferent }\end{array}$ \\
\hline & $\begin{array}{l}\text { Knowing ETC } \\
\text { systems }\end{array}$ & Do you know the Vía-T system? & $\begin{array}{l}\text { Yes } \\
\text { No }\end{array}$ \\
\hline
\end{tabular}

\section{References}

Abari, O., Vasisht, D., Katabi, D., Chandrakasan, A.: Caraoke: an E-toll transponder network for smart cities. Sigcomm 2015, 297-310 (2015). https://doi.org/10.1145/2785956.2787504

Abuzwidah, M., Abdel-Aty, M.: Safety assessment of the conversion of toll plazas to all-electronic toll collection system. Accid. Anal. Prev. 80, 153-161 (2015). https://doi.org/10.1016/j.aap.2015.03.039

Ben-Akiva, M., Bierlaire, M.: Discrete choice methods and their applications to short-term travel decisions. Handb. Transp. Sci. (2003). https://doi.org/10.1007/0-306-48058-1_2

Bip\&Drive, Vía-T annual report. Madrid, Spain (2016)

Bueno, P.C., Gómez, J, Vassallo, J.M: Seeking factors to increase the public's acceptability of road-pricing schemes: the case of Spain, 2017. Published in the Transportation Research Record: J. Transp. Res. Board (2017). doi: https://doi.org/10.3141/2606-02

Button, K.: Transportation planning on trial: The clean air act and travel forecasting: Mark Garrett and Martin Wachs. Sage Publications, CA, 232 pp. + vii (1996)

Caneschi, F.: CEN standardization of the electronic toll systems architecture, In: ITST 2007-7th International Conference on Intelligent Transport Systems Telecommunications, Proceedings. Pisa, Italy, pp. 357-361. (2007) doi:https://doi.org/10.1109/ITST.2007.4295893

Chang, E.C.P., Wu, M.F., Chang, Y.C.: Successful Taiwan freeway electronic toll collection (ETC) implementation through intelligent transport system (ITS). In: 11th Asia-Pacific Transportation Development Conference and 29th ICTPA Annual Conference. ASCE-American Society of Civil Engineers, Reston, VA, USA, Hsinchu, Taiwan, pp. 86-92. (2016)

De Grange, L., Gonzalez, F., Troncoso, R.: Estimates of price elasticity of demand for urban freeway use with high-frequency control variables: the case of Santiago, Chile. Appl. Econ. 47, 2326-2337 (2015). https://doi.org/10.1080/00036846.2015.1005825 
de Leeuw, J., Meijer, E. (eds.).: Introduction to multilevel models. In: Handbook of Multilevel Analysis. Springer (2007). https://doi.org/10.1007/978-0-387-73186-5

Eliasson, J.: Lessons from the Stockholm congestion charging trial. Transp. Policy 15, 395-404 (2008). https://doi.org/10.1016/j.tranpol.2008.12.004

Fowler, S., Bradley, J.E., Marquis, B.: Annual meeting of the transportation research board, Transp. Res. 01021011 (2006)

Golden Gate Bridge. Highway and transportation district, 2016. Golden Gate Bridge [WWW Document]. URL http://goldengate.org/tolls/. (2016)

Gomez, J., Papanikolaou, A., Vassallo, J.M.: Measuring regional differences in users' perceptions towards interurban toll roads. J. Transp. Geogr. 54, 22-33 (2016). https://doi.org/10.1016/j.jtrangeo.2016.05. 001

Gomez, J., Papanikolaou, A., Vassallo, J.M.: Users' perceptions and willingness to pay in interurban toll roads: identifying differences across regions from a nationwide survey in Spain. Transp. (Amst). (2015). https://doi.org/10.1007/s11116-015-9662-6

Gujarati, D.N.: Basic econometrics (2003)

Hayward, M.: Electronic toll collection systems in Europe. Clean Mobil. Intell. Transp. Syst. (2015). https:// doi.org/10.1049/PBTR001E_ch7

Heras-Molina, J., Gomez, J., Vassallo, J., 2016. Interoperability of electronic toll collection systems throughout Europe. Is it possible?, In: 6th Transport Research Arena. Warsaw, Poland

Hox, J.: Multilevel analysis: techniques and applications. Lawrence Erlbaum Associates, Hillsdale (2002)

Hsu, M., Shih, A.: A traffic signal control mechanism in a connected vehicle environment. 2015 IEEE International Conference on Consumer Electronics - Taiwan, Taipei, Taiwan, pp. 256-257. (2015). https.//doi.org/10.1109/ICCE-TW.2015.7216885

Huang, C., Burris, M.W.: The short-run impact of gas prices fluctuations on toll road use. Case Stud. Transp. Policy 3(2), 137-150 (2015)

Infraestruturas de Portugal: Portugal Tolls [WWW Document]. URL http://www.portugaltolls.com/web/ portal-de-portagens/home. (2016)

Jaensirisak, S., Wardman, M., May, A.: Explaining variations in public acceptability of road pricing schemes. J. Transp. Econ. Policy 39(2), 127-153 (2005)

Jardí-Cedó, R., Castellà-Roca, J., Viejo, A.: Privacy-preserving electronic toll system with dynamic pricing for low emission zones. Lect. Notes Comput. Sci. (including Subser. Lect. Notes Artif. Intell. Lect. Notes Bioinformatics) 8872, 327-334 (2015) doi:https://doi.org/10.1007/978-3-319-17016-9_22

Jou, R.-C., Chiou, Y.-C., Ke, J.-C.: Impacts of impression changes on freeway driver intention to adopt electronic toll collection service. Trans. Res. Part C Emerg. Technol. 19(6), 945-956 (2011)

Jou, R.C., Chiou, Y.C., Kuo, C.W., Tan, H.I.: Freeway drivers' willingness to pay for an on board unit under an electronic toll collection system. Transp. Res. Part C Emerg. Technol. 27, 16-24 (2013). https://doi. org/10.1016/j.trc.2012.11.002

Jou, R.C., Huang, G.L.: Willingness to pay price for tolls and on-board units for short-distance freeway users who normally avoid toll boots. Transp. Policy 31, 10-18 (2014). https://doi.org/10.1016/j.tranpol.2013. 11.001

Kaparias, I., Bell, M.G.H.: London congestion charging: successes, gaps and future opportunities offered by cooperative ITS. IEEE Conf. Intell. Transp. Syst. Proc. ITSC (2012). https://doi.org/10.1109/ITSC. 2012.6338687

Kottenhoff, K., Brundell Freij, K.: The role of public transport for feasibility and acceptability of congestion charging - the case of Stockholm. Transp. Res. Part A Policy Pract. 43, 297-305 (2009). https://doi. org/10.1016/j.tra.2008.09.004

Koppelman, F.S., Bhat, C.: A Self Instructing Course in Mode Choice Modeling: Multinomial and Nested Logit Models. Prepared for the US Department of Transportation, Federal Transit Administration, Washington D.C (2006)

Limelight. 2012 Road User Satisfaction Survey (2012)

Louviere, J.J., Street, D., Burgess, L., Wasi, N., Islam, T., Marley, A.A.J.: Modeling the choices of individual decision-makers by combining efficient choice experiment designs with extra preference information. J. Choice Model. 1, 128-164 (2008). https://doi.org/10.1016/S1755-5345(13)70025-3

Matas, A., Raymond, J.L., Ruiz, A.: Traffic forecasts under uncertainty and capacity constraints. Transp. (Amst). 39, 1-17 (2012). https://doi.org/10.1007/s11116-011-9325-1

Memarian, B., Jeong, D.H.S., Uhm, D.: Effects of survey techniques on on-board survey performance. Transp. Policy 21, 52-62 (2012). https://doi.org/10.1016/j.tranpol.2012.01.006

Ministerio de Fomento: Los Transportes y Las Infraestructuras: Informe Anual 2015, pdf. ed. Madrid, Spain (2016) 
Mizutani, F., Uranishi, S.: Privatization of the Japan highway public corporation: focusing on organizational structure change. Transp. Rev. 28, 469-493 (2008). https://doi.org/10.1080/01441640701791749

Odeck, J., Kjerkreit, A.: Evidence on users' attitudes towards road user charges-a cross-sectional survey of six Norwegian toll schemes. Transp. Policy 17, 349-358 (2010). https://doi.org/10.1016/j.tranpol.2010. 04.001

Papadimitriou, C.: Algorithms, complexity, and the sciences. Proc. Natl. Acad. Sci. 111(45), 15881-15887 (2014)

Persad, K., Walton, C., Hussain, S.: Electronic vehicle identification: industry standards, performance, and privacy issues, 1-3, (2007)

Rienstra, S.A., Rietveld, P., Verhoef, E.: The social support for policy measures in passenger transport. Transp. Res. Part D Transp. Environ 4(3), 181-200 (1999)

Saber, T., Ventresque, A., Murphy, J.: ROThAr: real-time on-line traffic assignment with load estimation, In: Proceedings of IEEE International Symposium on Distributed Simulation and Real-Time Applications. pp. 79-86. (2013) doi:https://doi.org/10.1109/DS-RT.2013.17

Schade, J., Baum, M.: Reactance or acceptance? Reactions towards the introduction of road pricing. Transp. Res. Part A Policy Pract. 41, 41-48 (2007). https://doi.org/10.1016/j.tra.2006.05.008

The European Parliament, The Council: Directive 2004/52/EC of the European Parliament and of the Council of 29 April 2004 on the interoperability of electronic road toll systems in the Community. Strasbourg, 29 April 2004, (2004)

Train, K.E.: Discrete Choice Methods with Simulation, pp. 1-388. Cambridge University Press, Cambridge (2003). https://doi.org/10.1017/CBO9780511753930

Yim, Y.: Electronic Toll Collection System (ETC) User Survey. CA, EEUU, Berkeley (1991)

Javier Heras-Molina is civil servant at the Spanish Public Works Ministry and PhD candidate. His research activities focus on ITS technologies, electronic toll collection and transport modelling. He has participated in different international meetings such as TRB or TRA and consultancy projects in the transport area.

Juan Gomez is Assistant Professor at the Civil Engineering School (UPM). His research activities focus on transport economics, road charging, electronic toll collection and transport modelling. He has published 10 papers in prestigious journals and participated in consultancy projects in the transport area.

José Manuel Vassallo is Professor at the Civil Engineering School (UPM). His research activity mainly focuses on transportation management and financing, infrastructure regulation, and public-private partnerships. He has published 6 books and more than 30 papers in prestigious journals. 